\title{
Telemedicine Requirements for Treatment Network in Oman
}

\author{
Mohammad Hameed Altaei and Ziyad T. Abdul-Mehdi
}

\begin{abstract}
Telemedicine systems in Oman are not in wide use due to the shortage of expert people working in this field, and the misunderstanding of the capabilities of this technology in improving treatment with lower cost. The objective of this paper is to propose a telemedicine system "Digital Medical Center (DMC)" that covers all the cities of Oman with telemedicine facilities. DMC is a simple and easy-to-implement, and economically affordable alternative to the current systems; the aim is to improve the medical treatment in Oman and to put the advanced medical diagnosis in the world between the patient hands in Oman through the internet.

The partners of this system connected by a Medical Treatment Network that based on the International Telecommunication Network and administrated by Digital Hospital which is an interface between all the hospitals in and outside Oman. This system is developed in client-server architecture with a powerful security features. The prototype design, requirements, description, and security of the system are discussed in this paper.
\end{abstract}

Index Terms-Telemedicine, telediagnosis, teleradiology, medical treatment, digital hospital.

\section{INTRODUCTION}

These are challenging times for hospital industry. This paper provides a prototype of digital hospitals in Oman. The scope of research includes both new digital hospitals and hospitals that are transforming specific processes or departments using innovative technological approach.

The proposed digital hospitals used to help validate any conclusion and gain some perspective into what the future might hold. Important facilities that be presented to the patients are [1]:

- Patients should receive care wherever they need it and in many forms, not just face -to-face visits.

- Patients should be able to get his individual choices and preferences from the network.

- Patients should be given the information they need to exercise control over decisions that affect them.

- Patients should have unfettered access to their own medical information and to clinical knowledge.

- Patients should be able to communicate effectively and share information with clinicians.

- Patients should care based on the best available scientific knowledge.

- Patient's time should not be wasted by health system.

A Teleconsultation system is a type of telemedicine application used by physicians to inspect the medical data of

Manuscript received March 25, 2013; revised May 25, 2013.

The authors are with IT Department, Applied Sciences College, Sohar, Oman (e-mail: mohammad.soh@ cas.edu.om,ziyad.soh@ cas.edu.om). the patients located in remote areas. Teleconsultation may be performed either in real-time or asynchronously.

In real time teleconsultation specialized medical staff located in large care centers of urban areas inspects the vital signals and images of the remote patients in real time and makes a diagnosis immediately. In the asynchronous case, on the other hand, the expert usually accesses medical data at a later convenient time [2]. Therefore, an apparent advantage of the asynchronous systems is the elimination of the need to schedule the telemedicine contact.

\section{TELEMEdicine SYSTEM REQUiREMENTS}

A telemedicine system has a unique set of requirements [3]. The requirements can be divided into the following categories:

- Telemedicine workstation: Telemedicine system requires programmable video, audio, image handling and compression to support applications ranging from typical video teleconferencing to provide " diagnostic-quality" video, audio, and medical images interactively. Typically required functions are MPEG (for a high quality audio/video compression), JPEG (for image compression). In addition, the acquisition, compression and processing, and the communication interface need to be tightly integrated to provide the necessary system efficiency.

- Communication network: In order to maximize the utilization of the available transmission medium (from land-based fiber optic cable to satellite link) while providing the best quality video and audio, the system should adapt to a wide variety of band widths, depending on the clinical application, the more challenging and difficult the remote consultation and diagnosis, the higher bandwidth the clinical application will require to provide better quality services.

- Human perception of media: In order to support an effective interaction through the telemedicine system, the latency of communication should be minimized. It has been reported [4] that lead/lay between the audio and video playback should be less than $80 \mathrm{msec}$ to perceive as synchronized by human observers. In case of full duplex communication, both audio/video should arrive no later than $80 \mathrm{msec}$.

\section{Telemedicine SECURITY}

Data security should be one of the highest priorities for any health care services enterprise. Although security regulations for the Health Insurance Probability and Accountability Act of 1996 (HIPAA) have only recently been finalized [5]. 
The Computer Security Institute (CSI) and the FBI study showed that $60 \%$ of all security breaches are "inside jobs" [6]. Sometimes the network is compromised by employees who do not have malicious intent, but whose carelessness opens the network to attack. The primary elements in security electronic data are the authentication of a user attempting to gain access to certain data, confidentiality of data as it is sent over a communication network, and integrity of the data.

\section{A. Firewalls}

For many businesses, firewalls are the primary choice for preventing external attacks on the communications system. While firewalls do serve an important role, they should not be relied on exclusively for total security. Thus, the firewall itself will not keep a worker in billing from seeing a patient's psychiatric records. Furthermore, wireless communication can compromise firewalls.

\section{B. Virtual Private Networks (VPNs)}

Virtual Private Networks (VPNs) are a solution that many medical facilities are choosing for their external communication because of lower costs and greater security capabilities. One of the key elements of VPNs is the encryption of data, so if data sent over a VPN is shielded from other transmissions through "tunneling ".

\section{C. $I P S e c$}

It has been the most important protocol for internet communications because it provides authentication of the origin of data, data content confidentiality, and anti-replay protection. IPSec adds information, an authentication header (AH) and encapsulating security page load (ESP), to the data packet before the packet is sent.

\section{D. $S S L$}

A growing number of readers are offering VPNs with Secure Sockets Layer (SSL). SSL uses a "handshake," which is initial communications between the sender (client) and receiver (server) to authenticate one or both parties at each end of the connection. Once the authentication has been established, confidentiality is provided through encryption, and data integrity is protected with a "wrapper" so that it cannot be modified in transit [7].

\section{TRANSFORMING TRADITIONAL TREATMENTS INTO Digital Hospitals}

TABLE I: STATISTICAL CAPABILITIES OF TREATMENT IN OMAN

\begin{tabular}{|l|l|c|c|c|}
\hline & Hospital-Type & $\begin{array}{c}\text { Number } \\
\text { of } \\
\text { hospitals }\end{array}$ & $\begin{array}{c}\text { Number } \\
\text { of beds }\end{array}$ & $\begin{array}{c}\text { Population/ } \\
\text { bed }\end{array}$ \\
\hline $\begin{array}{l}\text { Hospitals in } \\
\text { the capital } \\
\text { (Muscat) }\end{array}$ & $\begin{array}{l}\text { Governmental } \\
\text { and Private }\end{array}$ & 6 & 1394 & 672 \\
\hline $\begin{array}{l}\text { Hospitals in } \\
\text { all other } \\
\text { cities of } \\
\text { Oman. }\end{array}$ & $\begin{array}{l}\text { Governmental } \\
\text { and Private }\end{array}$ & 44 & 3298 & 667 \\
\hline $\begin{array}{l}\text { Health } \\
\text { Center }\end{array}$ & Governmental & 70 & 145 & -- \\
\hline Total & & $\mathbf{1 2 0}$ & $\mathbf{4 8 3 7}$ & $\mathbf{6 7 0}$ \\
\hline
\end{tabular}

In Oman, telemedicine system is not in wide use mainly because of the high costs and the technical complexity. Lack of such systems has serious implications such as the costly travel expenses and, more importantly, the delay that occurs during transportation that could lead to disease progression.

The Study can define the digital hospitals as an application of information technology to improve the processes of treatments through the world with cheapest cost. The number of the hospitals with their capacity of beds of treatments in Oman according to the last statistical in 2010-2011 are as shown in Table I [8].

Regarding the above table we found that the ratio in Oman is (670) persons for each hospital's bed, where in Japan the ration is one bed to each (75) persons, while in USA the ratio is (340).

The Kaiser Family Foundation reports of year 2011 (http://www.globalhealthfacts.org) shows that the number of hospital beds per each 10,000 population in Oman are (18) beds while in Japan (137) beds, and in USA (30) beds. Comparing with the global ratio (30) beds the shortage in Oman is around (12) beds to reach this ratio.

Table II shows the statistical survey of the number of physicians and assist of medicinal in Oman. Comparing g with the international ratio (for each 1000 person) Oman has (1.9), USA (2.4), Japan (2.1), and Georgia (4.8) physicians. (http://data.worldbank.org/indicator/SH.MED.PHYS.ZS)

TABLE II: StatistiCAL SURVEY OF THE HUMAN WORKING IN MEDICAL FIELD IN OMAN

\begin{tabular}{|l|c|c|}
\hline & Total & $\begin{array}{c}\text { Population } \\
\text { per each }\end{array}$ \\
\hline Physicians & 5862 & 500 \\
\hline Nurses (Male and Female) & 12865 & 228 \\
\hline
\end{tabular}

The above shortage in beds and physicians with addition to the shortage in some medical specialists can be compensated partially by Telemedicine services, so we proposed in this paper a prototype for such system. The proposed Digital Hospital will improve the capability of treatment by the capability to contact the specialist physicians, who are not available in the countries such as in Oman.

\section{CURRENT TELEMEDICINE SySTEM In OMAN}

Some of special Telemedicine system is available in Oman, but these systems are limited to some hospitals or centers not for all and these are for specified diseases and specialization using a specified application such as Teleradiology, consultation, monitoring and so on. In the following will mention some of these systems with their features and equipments.

\section{A. Apollo Telemedicine Network (ATN)}

The largest telemedicine network in the region, it is inaugurated by former US president Bill Clinton in 2000 in Hyderabad. It is the country's first telemedicine service in the private sector in Oman, set up by Muscat-based Apollo Medical Centre (AMC) in league with the Apollo Group of Hospitals [9]. 
This is a milestone in healthcare relations between Oman and India; Oman became the 145th telemedicine centre connected with the Apollo Group of Hospitals in India's southern state of Andhra Pradesh. Dr. Reddy said that, now patients from Oman can first consult experts in India through 24-hour telemedicine service before travelling for treatment.

Apart from video consultation, specialists in India can review investigations of patients in Oman [including laboratory tests, X-ray, sonogram, CT scan and MRI] and give a comprehensive opinion to patients.

\section{B. Badr Al-Samaa Telemedicine Centre}

Badr Al-Samaa in Ruwi is one of the largest private hospital groups in Oman, and the telemedicine center is the first of its kind in the country's private sector. The center plans to make telemedicine services available from only different hospitals in India but also from various parts of the globe such as Thailand and Singapore[10].

The new branch, coming up in Al-Khoud, will have super-specialties like cardiology and urology with most modern operation theatre complex and maternity. Badr Al-Samaa also offering the video conferencing solution.

\section{Suggested Medical Treatment Network (Digital HOSPITAL)}

In order to improve the medical treatment in Oman and to increase its capability to cover all distance places from the capital and to put the advanced medical diagnosis in the world between the patient hands in Oman, with the help of new technology, the study suggest a Medical Treatment Network that based on the International Telecommunication Network. This treatment depends on the digital transformation of the patient's data and it is administrate by Digital Hospital which is an interface between all the hospitals in and outside Oman, and through which all the information between patients, physicians, and other medical sides are transmitted and saved.

Patients in Oman can deal with any hospital (Private or Government) either electronically or personally. Fig. 1 illustrates this network (Digital Hospital).

The Treatment Network Connect the followings;

- Private Hospital and Clinical (P.H).

- Government Hospital and Clinical (G.H).

- World-Wide Hospitals.

- Digital Medical Center.

The first four hospitals each one must have the following equipment:

- Web-Cam.

- X-Ray

- Scanner and Printer.

- Personal Computer with internet connection.

- Analysis Titration.

The Digital Medical Center contains the following equipment:

- E-mail Server.

- Web-site Server.

- Private Hospital (P.H.) Server.

- Government Hospital ( G.H.) Server.

- Military Hospital (M.H) Server.

- Fire Wall Router.
- Internet Connection.

\section{SYSTEM DESCRIPTION}

The system scenario is; there are four types of users are identified to use the system:

- Specialist physicians in medical complexes located in urban areas.

- Medical staff in local clinics located in selected towns or villages in remote and underserved areas.

- Patients in any towns or villages in any areas in Oman.

- Network technical people in the Medical Center.

The internet connection is required to run a web browser like Internet Explorer or Netscape Navigator. Since these popular web browsers are equally supported by different computer systems, it should be noted that the system is not designed with the aim of serving only a specific group of patients. The system designed to serve all kinds of patients.

In the scenario, the patient comes to a local clinic, where biological and physiological data acquire data and examine them. The ministry of health should be determined the locations of these clinics to be easily reach by patients. The clinics should be supplied with relatively simple clinical measurement devices to obtain the basic medical data like blood pressure, body temperature, glucose level, pulse rate, weight, ECG/EEG records, x-ray, and ultrasound machines.

The role of the medical staff is to capture data from patients, upload them in a central data base. The experts located at large medical complexes, on the other hand, would normally use the system to access the on-line monitoring web pages and to import the requested patient data from the central data base where they are saved routinely by the local clinic staff.

Since the system works asynchronously, the expert, after inspecting the received studies of their remote patients at some moment during the day, could reply the decision using phone, fax, e-mail, chat ...etc. in any time.

Fig. 1 shows the different elements that provide the remote monitoring environment. The DMC could be located at a specific location in the capital city of Muscat; the components of the center are the data base server and web server, which can be implemented in more than one computer.

In order to provide the services of the system, several components work in parallel.

- Data capture component; that is normally specific to the source of data.

- Strong component; that can rapidly store and retrieve large data objects into disk.

- Data object cataloging components; that automatically generates derived data, organizes collections of objects, and presents the information via a WWW user interface.

- Network component linking all the distributed components into a single system.

A telemedicine prototype have developed is a Digital Medical Center (DMC) with multimedia capabilities for teleconferencing. Each workstation must be connected via fiber-optic cable to the Digital Medical Center (DMC). Each switch in the DMC must be connected to the other work-station in the hospitals in the capital Muscat or other states of Oman via fiber optic. The DMC can be connected to other countries via the satellite communication. 


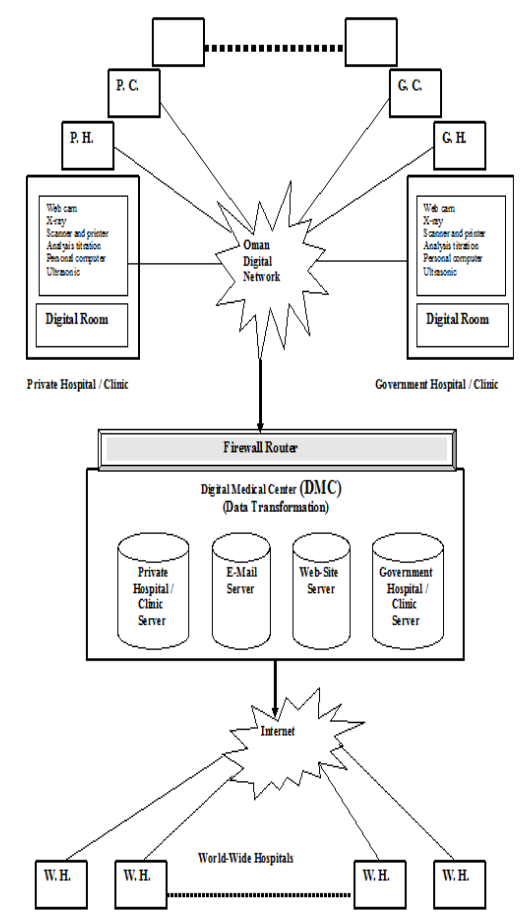

Fig. 1. A Suggested medical treatment network in oman

\section{CONCLUSION}

The paper presents the design of prototype remote monitoring system that could be effectively used to connect the governmental and private hospitals in all the Omani cities with the Digital Medical Center (DMC), via the Omani communication network. The DMC is located at the capital city Muscat. The center is connected to enables the physician in Omani hospital to contact with other hospital in the other countries via the satellite communication. The system can be developed with low cost especially it can use free software, and use popular web browsers like Internet Explorer and Netscape Navigator. The system is Internet based which is reduces the communication expenses and make the system platform independent and secure, as well as the system is easy to use, the only requirement to the users are to have a connection to the internet, run a browser and get permission required for asking physicians or by audio and video capabilities.

The system can also provide the patient records as well as the capability of managing physiological signals such as blood pressure, body temperature, pulse rate and biological data such as glucose level. It could manage more complex signal like EEG, EKG, X-ray and ultrasound.

One of the key results of the proposed system is that the system could be a means of providing better quality health care in underserved region in Oman and other developing countries. This will increase the probability of treatment as well as reduce the time lost during the travel, which can cause the disease to progression.

\section{REFERENCES}

[1] E. Drazen and J. Fotin, "Digital hospitals move off the drawing board," California Healthcare Foundation, pp. 4-16, 2003.

[2] C. Lau, S. Churcill, J. Kim, F. A. Matsen III, and Y. Kim, "Asynchronous web-based patient- centered home telemedicine System," IEEE Trans. Biomed. Eng., vol. 49, no. 12, pp. 1452-1462, 2002.

[3] D. Kim, J. E. Cabral Jr., and Y. Kim. Networking requirements and the role of multimedia systems in telemedicine. Image Computing System laboratory. [Online]. Available: http://www.fizzle.ee.washington.edu

[4] R. Steinmetz and C. Engler, "Human perception of media synchronization," IBM ENB Tech. Rep., n.43-9310, Heidelberg, 1993

[5] E. Friedman MS MIM, "Telemedicine and Telehealth Articles," Telehealth Practice Report, vol. 8, no. 4, pp.10-11, March/April 2003.

[6] Birkholz, Internal network security, Found stone, 2002.

[7] M. Rolllender, SSL: The secret handshake of the net, Network World, February 3, 2003.

[8] Annual Health Report, Directorate General of Planning, Ministry of Health, Sultanate of Oman, 2012.

[9] Oman sets up first telemedicine centre. [Online]. Available: http://gulfnews.com/news/gulf/oman/oman-sets-up-first-telemedicine -centre-1.194488

[10] MENAFN.COM.

[Online].

Available: http://www.menafn.com/menafn/1093161741/Badr-Al-Samaa-launch es-telemedicine-centre--Oman

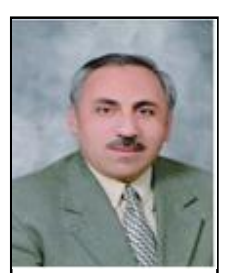

Mohamad Hameed Ahmed Al-Taei was born in Iraq 1962. He earned the Ph. D. Degree in Computer Applications ( Telemedicine ) from Zhejiang University, China in 1999, M.Sc. Degree in Computer Science ( Computer Arithmetic) from Mosul University, Iraq in 1990, and B.Sc. Degree in Mathematics from Mosul University, Iraq in 1984.

He worked as Head of Information Technology Department in Applied Science College , Sohar Oman (2010-2012), currently he is an assistant professor in the same College (www.cas.edu.om). From (1999-2008) he worked as an Assistant Professor in the faculty of Information Technology in Applied Science University (ASU.eud.jo) and Zarka Private University (ZPU.edu.jo) in Jordan , and from (1991-1996) as an Assistant Lecturer in Mosul University, Iraq.

Dr. Al-Taei has published articles in International journals and conferences on topics of Computer Arithmetic, Computer Applications and Telemedicine applications.

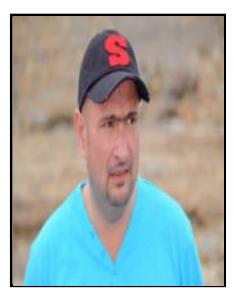

Ziyad Tariq Abdul-Mehdi is currently a senior assistant professor in Department of Information Technology (IT), Sohar College of Applied Science, Sultanate of Oman. He Holds Post.Doc in Database Security (2008), Ph.D. Awards in Computer Science (Mobile Database Systems 2007) and Ms. Degree in Computer Science (Distributed System 2003) from University Putra Malaysia (UPM), selangor, Malaysia and a B.S. in Computer Science from Mansour University College (MUC 1993), Baghdad, Iraq.

He has published articles in International journals and conferences on topics in database systems, Transaction management, Security replication, e-government and information ethics. Dr. Ziyad is a member of the Evaluation Committee and Board editor in IETECH (International Journal for Engineering and Technology) as well as member for paper evaluator for many international conferences such as international conference Science of Electronics, Technologies of Information and Telecommunications (SETIT'2007), M2USIC2007 and many other international conferences. 